\title{
GESTÃO E PLANEJAMENTO EM EAD: MODELO DE SISTEMA DE INFORMAÇÕES DA MATRIZ DO DESIGN EDUCACIONAL (MADE)
}

\author{
Lívia Maria de Lima Santiago ${ }^{1}$ \\ Débora Liberato Arruda Hissa ${ }^{2}$ \\ Cassandra Ribeiro Joye ${ }^{3}$
}

\begin{abstract}
RESUMO: Neste artigo, apresentamos um sistema de gestão e planejamento para as disciplinas dos cursos na modalidade a Distância (Made). Trata-se de um sistema de informações que atua como ferramenta de apoio na elaboração e no planejamento da Matriz de Design Educacional das disciplinas a distância. Ele possibilita a seus usuários (alunos, professores e gestores) sistematizar os processos educacional, gerenciar os trabalhos acadêmicos e organizar o fluxo de mensagens entre os sujeitos envolvidos nas disciplinas. Como base teóricas, estudamos os modelos pedagógicos de Behar (2009); a metodologia colaborativa de Joye e Young (2013); o Design instrucional de Filatro (2003); a Engenharia Pedagógica de Paquette (2002) e a Engenharia de Requisitos de Pressman (2010). Para o desenvolvimento do sistema, foram realizadas reuniões periódicas com a equipe de desenvolvimento.
\end{abstract}

Palavras-chave: Planejamento em Educação a Distância. Matriz de Design Educacional. Sistema Made.

\section{MANAGEMENT AND PLANNING IN EAD: MODEL OF INFORMATION SYSTEM OF EDUCATIONAL DESIGN MATRIX (MADE)}

\begin{abstract}
In this article, we present a management and planning system for the disciplines of distance learning (Made). It is an information system that acts as a support tool in the design and planning of the Educational Design Matrix of distance disciplines. It enables its users (students, teachers and managers) to systematize educational processes, manage academic work and organize the flow of messages among the subjects involved in the subjects. As theoretical basis, we study the pedagogical models of Behar (2009); the collaborative methodology of Joye and Young (2013); Instructional Design by Filatro (2003); the Pedagogical Engineering of Paquette (2002) and the Requirements Engineering of Pressman (2010). For the development of the system, periodic meetings were held with the development. Keywords: Planning in Distance Education. Matrix of Educational Design. Made system.
\end{abstract}

\footnotetext{
${ }^{1}$ Mestre em Computação Aplicada pela Universidade Estadual do Ceará (UECE). Designer Educacional na Diretoria de Educação a Distância do Instituto Federal de Educação, Ciência e Tecnologia do Ceará (IFCE)

${ }^{2}$ Mestre e doutora em Linguística Aplicada pela Universidade Estadual do Ceará.

${ }^{3}$ Mestre e doutora em Engenharia de Produção pela Universidade Federal de Santa Catarina pela Universidade Federal de Santa Catarina (UFSC). Professora do Instituto Federal de Educação, Ciência e Tecnologia do Ceará (IFCE).
} 


\section{INTRODUÇÃO}

Em Educação a Distância $(\mathrm{EaD})$, o planejamento para oferta das disciplinas ocorre em um momento bem anterior à execução do curso, através da ação colaborativa dos sujeitos envolvidos (docentes, discentes e gestores). Essa ação de planejar e executar envolve desde a coordenação do curso responsável pela lotação dos professores, passando pela equipe de Design Educacional, equipe web, chegando até aos professores tutores responsáveis por conduzir a disciplina junto aos alunos.

A Diretoria de Educação a Distância do Instituto Federal de Educação, Ciência e Tecnologia do Ceará (DEaD/IFCE) adota como modelo para o planejamento das disciplinas dos seus cursos a distância o documento da Matriz de Design Educacional. Este documento se utiliza de um editor de texto, o que implica em tempo com upload e download de arquivos e uma limitação no controle de produção das matrizes. Como há quantidade significativa de disciplinas ofertadas semestralmente, o volume de documentos produzidos e profissionais envolvidos também é numeroso, o que torna o processo de gestão da produção da matriz uma tarefa complexa.

Para atender a essa demanda, a $\mathrm{DEaD}$ conta com a colaboração de uma equipe multidisciplinar composta por diversos profissionais, entre eles conteudistas, designer educacionais (DE), revisores, diagramadores, tutores a distância e presencial, coordenador de curso, coordenador de polo, dentre outros. Essa equipe é responsável pela produção e oferta das disciplinas dos cursos a distância da DEaD. A Matriz de Design Educacional é um documento utilizado como apoio ao planejamento das disciplinas e vem sendo usado desde 2009. Sua elaboração é de responsabilidade do professor formador, sob orientação pedagógica de um DE.

Semestralmente são ofertadas em torno de cento e oitenta disciplinas, de nível técnico, superior e pós-graduação, as quais requerem uma quantidade muito grande de matrizes e de profissionais envolvidos nos planejamentos. A produção da Matriz ocorre de forma offline e o meio de comunicação utilizado é o correio eletrônico. Para sua elaboração são trocados uma média de dez e-mails, o que totaliza uma média de 1800 emails durante o semestre. Desta forma, o acompanhamento da produção da Matriz torna-se uma tarefa complexa e exige um olhar atento do coordenador de produção, o que nem sempre é possível. Vale ressaltar que a composição desse documento não ocorre de modo isolado, mas sim através da colaboração e experiência de cada profissional envolvido. Além do professor formador e do designer educacional, a 
construção da Matriz conta com a atuação de um revisor. Esse ator é responsável pela correção ortográfica, sintática e textual do conteúdo proposto.

Para o gerenciamento desses materiais, a equipe multidisciplinar estabelece processos, rotinas e documentos que lhe permitam fazer uso desses conteúdos em outras situações didáticas. Contudo, o grande fluxo de informações produzidas diariamente, impõe à equipe a adoção de outros mecanismos que otimizem os processos e possibilitem a rápida localização dos materiais. Com o propósito de organizar, planejar e sistematizar todo o fluxo de produção da Matriz de Design Educacional, propomos o desenvolvimento de um sistema informatizado que concentre todos os programas, cursos, disciplinas, profisssionais e proporcione aos atores a construção da Matriz de forma online, centralizada em um ambiente próprio, além de possibilitar ao coordenador de produção o compartilhamento e gerenciamento das matrizes produzidas e em produção.

\section{GESTÃO DE CURSOS NA MODALIDADE A DISTÂNCIA}

$\mathrm{Na}$ construção desse modelo voltado para a Educação a Distância, cada instituição de ensino precisa ponderar o uso das Tecnologias de Informação e Comunicação nos mais diferentes eixos do processo de desenvolvimento de seus cursos. Behar (2009, p. 25) destaca aspectos essenciais no que concerne à estruturação de um modelo pedagógico: "aspectos organizacionais; conteúdo - objeto de estudo; aspectos metodológicos; aspectos tecnológicos". Além disso, é preciso considerar todos os aspectos que envolvem o uso dessas tecnologias como suporte aos cursos.

Em Educação a Distância, o planejamento ocorre em um momento bem anterior à execução do curso e/ou disciplina, através da ação colaborativa dos atores envolvidos. Delimitar todas as ações é uma tarefa imprescindível para o sucesso de qualquer curso, seja a distância ou presencial. Spanhol (2009, p. 412) ressalta que "o planejamento é o fio condutor da $\mathrm{EaD}$, pois, nessa modalidade de ensino-aprendizagem, o estudante é o centro do processo, obrigando a um planejamento detalhado das etapas de préprodução, produção e pós-produção do curso". Segundo Spanhol (2009), o desenvolvimento de um projeto em EaD é constituído basicamente por cinco fases: concepção, planejamento, execução, controle e fechamento.

Na fase de concepção, a proposta do projeto é gerada; são traçados os objetivos e metas; e é realizado o levantamento das necessidades de implementação desse projeto. 
A partir do Projeto Político Pedagógico estruturado, inicia-se a fase de planejamento. Nela os gestores responsáveis pela execução estabelecem cronograma, definem materiais didáticos e mídias utilizadas, contratam os profissionais que irão compor a equipe multidisciplinar e delimitam todas as atividades necessárias para $\mathrm{o}$ desenvolvimento das tarefas do curso.

A equipe multidisciplinar é formada por profissionais com perfis variados, passando por atores das áreas de tecnologia da informação, pedagógica, administração e outros setores mais específicos. Essa equipe é responsável pela produção dos materiais didáticos, distribuição desses materiais nas diferentes mídias (web, impresso, etc.), suporte e manutenção do ambiente virtual de aprendizagem, apoio aos estudantes em suas atividades entre outros. No quadro 1, apresentamos a relação dos profissionais que, em geral, compõem a equipe multidisciplinar de projetos em Educação a Distância.

\section{Quadro 1 - Equipe multidisciplinar}

\begin{tabular}{|l|l|}
\hline Profissional & Função \\
\hline $\begin{array}{l}\text { Coordenador } \\
\text { do curso }\end{array}$ & $\begin{array}{l}\text { Planejar, coordenar e acompanhar a execução das atividades } \\
\text { pedagógicas do curso em colaboração com as demais coordenações. } \\
\text { Participar das atividades de discussão e de elaboração dos documentos } \\
\text { necessários à gestão do curso. }\end{array}$ \\
\hline $\begin{array}{l}\text { Coordenador } \\
\text { pedagógico }\end{array}$ & $\begin{array}{l}\text { Atuar no acompanhamento pedagógico dos cursos ofertados. } \\
\text { Supervisionar e orientar professores na condução de suas atividades no } \\
\text { Ambiente Virtual de Aprendizagem. Acompanhar os alunos na } \\
\text { resolução de problemas referentes à execução de suas atividades nos } \\
\text { cursos. }\end{array}$ \\
\hline $\begin{array}{l}\text { Coordenação } \\
\text { de Tecnologia } \\
\text { da Informação }\end{array}$ & $\begin{array}{l}\text { Coordenar a equipe de desenvolvimento de software, fazer as escolhas } \\
\text { das tecnologias. Orientar a equipe de programadores e controlar os } \\
\text { processos e as tarefas. Identificar, documentar, gerenciar e solucionar os } \\
\text { problemas que possam surgir. Verificar cada etapa do projeto bem como } \\
\text { a finalização do projeto. }\end{array}$ \\
\hline $\begin{array}{l}\text { Professor- } \\
\text { Conteudista }\end{array}$ & $\begin{array}{l}\text { Elaborar o conteúdo escrito das aulas que compõem o curso. Analisar as } \\
\text { melhores maneiras de aproveitamento do conteúdo, estabelecendo } \\
\text { mecanismos e atividades para a avaliação dos alunos. }\end{array}$ \\
\hline $\begin{array}{l}\text { Professor- } \\
\text { tutores }\end{array}$ & $\begin{array}{l}\text { Coordenar as atividades acadêmico-pedagógicas do curso. Acompanhar } \\
\text { o andamento das atividades realizadas pelo estudante, auxiliando-o e } \\
\text { orientando-o nas dúvidas que surgem nas aulas, através do Ambiente } \\
\text { Virtual de Aprendizagem. }\end{array}$ \\
\hline $\begin{array}{l}\text { Educacional } \\
\text { DE) }\end{array}$ & $\begin{array}{l}\text { Analisar o conteúdo produzido pelo conteudista, adequando-o à } \\
\text { linguagem e ao formato de material EaD. Validar as correções } \\
\text { linguísticas e textuais feita pelo revisor ortográfico. Sugerir imagens, } \\
\text { icones e recursos de interação aos materiais. Revisar em alto nível de } \\
\text { detalhamento o material após a editoração do revisor. Acompanhar o }\end{array}$ \\
\hline
\end{tabular}




\begin{tabular}{|l|l|}
\hline & $\begin{array}{l}\text { processo de postagem das disciplinas no Ambiente Virtual de } \\
\text { Aprendizagem, bem como a produção das videoaulas complementares. }\end{array}$ \\
\hline Revisor & $\begin{array}{l}\text { Cuidar da qualidade textual do conteúdo, isto é, verificar se o texto } \\
\text { didático atende satisfatória e plenamente ao propósito esperado e às } \\
\text { expectativas do leitor, assim como às convenções da norma culta da } \\
\text { modalidade escrita da língua. Indicar (e, em algumas vezes, fazer) } \\
\text { alterações que ajudem o professor-conteudista a ser bem-sucedido no } \\
\text { seu projeto de dizer. }\end{array}$ \\
\hline $\begin{array}{l}\text { Diagramação } \\
\text { Web }\end{array}$ & $\begin{array}{l}\text { Adaptar o conteúdo redigido pelo conteudista/DE/Revisor para a mídia } \\
\text { web. }\end{array}$ \\
\hline $\begin{array}{l}\text { Administração } \\
\text { do Ambiente } \\
\text { Virtual de } \\
\text { Aprendizagem }\end{array}$ & $\begin{array}{l}\text { Organizar as atividades, alocar as turmas, administrar senhas e usuários } \\
\text { no AVA. }\end{array}$ \\
\hline $\begin{array}{l}\text { Equipe de } \\
\text { Arte, Criação e } \\
\text { Produção }\end{array}$ & Fazer a edição de vídeo e a ilustração das aulas. \\
Visual
\end{tabular}

Fonte: Elaborada pelas autoras.

A fase de execução do projeto é a etapa de implementação de todas as atividades propostas no planejamento. Podem ocorrer reajustes de cronograma e orçamento, desde que sejam embasados pelo plano inicial. Manter uma boa comunicação sempre atualizada, acompanhar o desenvolvimento das atividades e gerenciar o relacionamento harmonioso da equipe envolvida são algumas das atividades de um gerente de projeto (SPANHOL, 2009).

Em paralelo à execução, ocorre o controle. Nesta fase, o gestor do projeto deve estar em constante verificação das ações realizadas, observando se estão dentro do previsto, pensando em quais atitudes precisam ser tomadas para corrigir os possíveis entraves, que ferramentas devem ser incorporadas para otimizar os trabalhos, quais estratégias melhor se enquadram ao contexto para evitar atrasos e possibilitar que o projeto seja entregue no prazo estipulado, entre outras ações.

Por último, vem a fase do fechamento. Nesse momento, a equipe envolvida no desenvolvimento do projeto se reúne para elencar os acertos e os erros. Destacar as ações realizadas que contribuíram e podem ser aproveitadas em outros projetos, fazer uma avaliação dos trabalhos realizados e elaborar o relatório detalhado do projeto são exemplos das ações dessa fase.

Para a produção dos materiais didáticos, a equipe multidisciplinar, a partir das diretrizes estabelecidas pela gestão do curso, delimita suas estratégias para consolidação dessa produção. Constituem essas ações a elaboração do cronograma das atividades, a 
escolha das mídias para disponibilização dos conteúdos, a divisão da equipe para atender a demanda, etc. Todas essas atividades devem ocorrer em fase bem anterior à oferta das disciplinas.

No cenário da oferta de uma disciplina, assim como na produção dos conteúdos, o planejamento é um instrumento de suma importância, pois é através dele que serão detalhadas todas as ações para execução das atividades de ensino e aprendizagem. Ele também orientará a equipe técnica na configuração da disciplina no AVA. Esse planejamento será conduzido conforme o modelo pedagógico adotado pela instituição que servirá de norte para o desenvolvimento das atividades das equipes. Na próxima seção, detalharemos melhor sobre o papel do planejamento na oferta de cursos a Distância.

\section{PLANEJAMENTO DE CURSOS A DISTÂNCIA NA DIRETORIA DE EAD DO IFCE}

A engenharia pedagógica integra e se apropria das teorias e métodos do design educacional e estabelece um corpus metodológico para a produção e oferta em educação a distância. O termo Engenharia Pedagógica (EP) foi criado pelo pesquisador canadense Gilbert Paquette para explicar os processos de análise, concepção, desenvolvimento, validação, divulgação e gestão dos sistemas de aprendizagem. Paquette (2002, p. 107) define a EP da seguinte forma: "um método de apoio à análise, ao design, à implementação e ao planejamento da difusão dos sistemas de aprendizagem, incorporando as concepções, os processos e os princípios do design pedagógico, da engenharia de software e da engenharia cognitiva”4. A engenharia pedagógica é um método sistêmico que busca propor soluções para resolver os problemas relacionados à concepção de sistemas de aprendizagem (PAQUETTE, 2002).

O Instituto Federal de Educação, Ciência e Tecnologia do Ceará, por meio das suas 23 unidades, localizadas em diversas cidades do estado do Ceará, oferta diversas licenciaturas e bacharelados em variadas áreas do conhecimento. São oferecidos cursos em nível médio, técnico, tecnológico e superior, além de especializações e mestrados. Atualmente o IFCE, por meio da $\mathrm{DEaD}$, oferta três cursos superiores a distância pelo

\footnotetext{
${ }^{4}$ Tradução nossa.
} 
Programa UAB: Licenciatura em Matemática, Licenciatura em Educação Profissional e Tecnologia em Hotelaria.

$\mathrm{Na}$ produção do material didático (impresso e web), os atores envolvidos realizam o planejamento prévio do semestre a ser ofertado, atentando para os prazos de início das disciplinas e cuidando para que os materiais estejam disponíveis aos estudantes nesta data. Em paralelo, a equipe estrutura as atividades, estabelece os prazos internos e define os responsáveis pela elaboração de cada material. Todo esse planejamento ocorre de forma articulada com as coordenações de cursos.

O fluxo de produção $^{5}$ dos conteúdos didáticos obedece aos parâmetros estabelecidos nos Referenciais de Qualidade do MEC, mas também adota moldes e aspectos próprios desenhados pela equipe pedagógica da $\mathrm{DEaD}$ ao longo desses anos. Esse fluxo foi desenvolvido com o intuito de padronizar a elaboração dos conteúdos e direcionar a equipe multidisciplinar no desenvolvimento de suas atividades.

Após a etapa de produção dos conteúdos, ocorre a fase de oferta desses materiais, que consiste na sua disponibilização através do AVA. O planejamento nessa fase é decorrente do trabalho colaborativo entre professores-formadores e designer educacionais. Essa atividade, objeto desse trabalho, é desenvolvida através do documento de planejamento chamado Matriz do Design Educacional, que contém todos os dados referentes à configuração da disciplina, descrição das atividades, metodologia adotada, formato de avaliação, atores envolvidos e datas de execução.

Os planejamentos desenvolvidos pela equipe multidisciplinar tomam como base o modelo pedagógico adotado pelo IFCE. Esse modelo "é concebido para a aprendizagem de adultos segundo os princípios da Andragogia" (JOYE; YOUNG, 2013 , p. 21). A elaboração das atividades a serem desenvolvidas para o curso ou disciplina deve considerar as experiências vividas pelo estudante, estimulando sua autonomia e promovendo a troca de saberes entre professor-aluno, aluno-aluno e alunoconteúdo através da colaboração.

Segundo Joye e Young (2013, p. 22), "a metodologia colaborativa tem como fundamento a relação e troca de conhecimento entre os sujeitos aprendizes”. Isso significa que, ao planejar uma atividade através do AVA, o professor-formador deve elencar quais estratégias melhor se enquadram às necessidades dos aprendizes e que

5 Para saber mais informações sobre o fluxo, leia o trabalho de Guedes (2010), disponível em $<$ http://www.repositorio.ufc.br/bitstream/riufc/3098/1/2010_Dis_JFGuedes.pdf $>$. Acesso em: 22 jul. 2017.

6 “Andragogia é a arte e a ciência de ajudar o adulto a aprender” (JOYE, JOYE, 2013, p. 42) 
pode promover essa relação de troca. Vale ressaltar que, assim como na modalidade presencial, o planejamento é elemento indispensável na $\mathrm{EaD}$, tendo em vista que ele é elemento-chave para proporcionar o desenvolvimento das diferentes ações necessárias à execução dos cursos nessa modalidade.

\section{ENGENHARIA PEDAGÓGICA E O DESIGN EDUCACIONAL NA CONCEPÇÃO DO SISTEMA MADE}

Os elementos teóricos apresentados pelas duas abordagens, Engenharia Pedagógica e design educacional, contribuem para a estruturação do sistema Made, pois ambas possuem etapas de planejamento bem definidas. Por considerarem todo o contexto de ensino, requer análise e acompanhamento contínuo em todo o processo. $\mathrm{Na}$ figura 1, apresentam-se as fases que compõem o desenvolvimento do planejamento e oferta das disciplinas através do sistema Made.

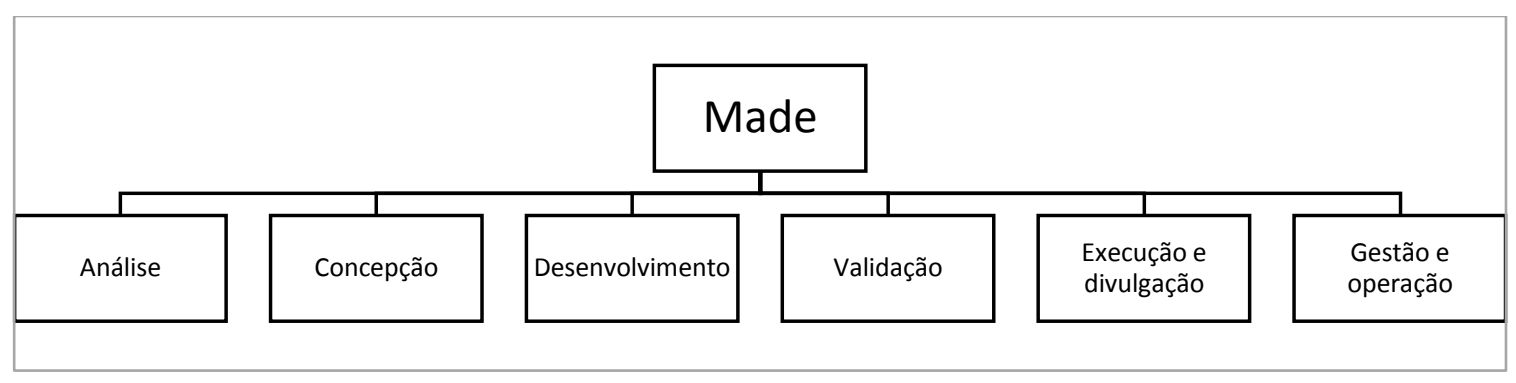

Figura 1 - Etapas de concepção do sistema Made

Fonte: Elaborada pelas autoras.

A elaboração da Matriz de Design Educacional das disciplinas através do sistema Made perpassa algumas etapas, desde um planejamento macro que envolve as coordenações de cursos onde se delimitam as ações comuns a todos os cursos até o planejamento micro que corresponde à elaboração da matriz de uma disciplina específica. A seguir são apresentadas as etapas que compreendem o planejamento macro para oferta das disciplinas, considerando o sistema Made como sistema de apoio a gestão desses planejamentos.

- Etapa de análise - nesse momento, a coordenação de curso é encarregada de selecionar os professores, delimitar o cronograma de execução das disciplinas, distribuir os encontros presenciais levando em consideração o orçamento disponível 
e, por fim, repassar à equipe de design educacional (DE) todos os dados necessários para concepção das próximas etapas.

- Etapa de concepção ou design - o administrador do sistema Made recebe os dados da coordenação de curso e realiza o cadastro das matrizes das disciplinas no sistema Made.

- Etapa de desenvolvimento - a equipe de design educacional inicia o processo de planejamento e elaboração da matriz juntamente com os professores-formadores responsáveis pelas disciplinas. É nessa fase que ocorrem todas as discussões pedagógicas entre o formador e o designer educacional que lhe acompanha.

- Etapa de validação - após todos os ajustes no conteúdo da matriz, o designer exporta a matriz produzida e encaminha ao diagramador web para postagem no ambiente virtual de aprendizagem (AVA).

- Etapa de execução e divulgação - nessa etapa, se produzem duas atividades em paralelo: $1^{\circ}$ o DE comunica ao formador que sua sala virtual no AVA está pronta, podendo iniciar as interações com os alunos; $2^{\circ}$ o administrador do sistema Made verifica se há pendências nas matrizes finalizadas e continua no suporte às matrizes em desenvolvimento.

- Etapa de gestão e operação - a equipe de administração do sistema cuida das atualizações, do suporte aos usuários e dos ajustes técnicos que porventura possam surgir.

Dentre as fases apesentadas acima, destaca-se a fase de desenvolvimento da matriz de uma disciplina, pois é nessa etapa que ocorre todo o design educacional da disciplina. O planejamento é realizado levando em consideração o modelo ADDIE proposto por Filatro (2003). Dentro do processo de planejamento e elaboração de uma matriz, as fases apresentadas na figura 10 orientam os atores nos seguintes aspectos:

- Análise - o professor formador define os objetivos (geral e específico) da disciplina levado em consideração o público e a relevância do conteúdo para a formação discente.

- Design - criação da equipe pedagógica composta por tutores a distância e presenciais, responsáveis, respectivamente, pelo acompanhamento dos alunos no AVA e pelo apoio no polo presencial. Também nessa fase são elencadas as 
estratégias didáticas e ferramentas tecnológicas que servirão de apoio à execução das atividades.

- Desenvolvimento - professor formador preenche os campos das atividades, fazendo os devidos ajustes e adequações na linguagem e no formato para uma disciplina na modalidade a distância. Estabelece como e quando ocorrerão as atividades, como o aluno será avaliado e quanto será atribuído em \% para cada atividade avaliativa. Além disso, orienta os tutores a distância sobre a execução da disciplina e reajusta o planejamento, caso considere pertinente.

- Implementação - com a matriz finalizada e suas informações configuradas no AVA, o formador inicia seu trabalho de acompanhamento e suporte às atividades dos tutores a distância.

- Avaliação - ocorre durante todo o processo de construção da matriz e posteriormente na sua aplicação junto aos alunos. Tanto o formador da disciplina quanto a equipe de design educacional (re)analisa as etapas de concepção da matriz e da aplicação das atividades propostas revendo o que foi satisfatório e os entraves durante o processo.

Como pode ser observado, a oferta de disciplinas na modalidade a distância requer o envolvimento de diversos atores trabalhando de forma sincronizada. $\mathrm{O}$ intuito desse trabalho colaborativo é oferecer aos discentes um material de qualidade que contribua para seu processo de aprendizagem e esteja disponível em tempo hábil ao início do seu curso.

A coordenação de produção de cada projeto necessita, em suas atribuições, realizar o acompanhamento de todas as matrizes produzidas, possibilitar que os trabalhos realizados pelos colaboradores aconteçam em tempo hábil e diluir possíveis entraves pedagógicos e técnicos que apareçam no percurso. Da necessidade de sistematizar essas ações surgiu a proposta de construção do Sistema Made. Tomando como base o documento da Matriz de Design Educacional já existente e utilizado no contexto da $\mathrm{DEaD} / \mathrm{IFCE}$, o Sistema Made permite a elaboração dos planejamentos de forma colaborativa, totalmente online e proporciona a criação de um banco de dados para gerenciamento e compartilhamentos futuros. 


\section{DESCRIÇÃO DA PROPOSTA E REQUISITOS DO MADE}

A elaboração do sistema demandou reuniões sistemáticas entre as equipes pedagógica e técnica. $\mathrm{O}$ objetivo desses encontros, em momento inicial à pesquisa, foi realizar o levantamento de todos os requisitos que subsidiariam a construção do Sistema Made. A etapa de montagem da "engenharia de requisitos" é fundamental para o bom andamento de um projeto (PRESSMAN, 2010). Conforme Pressman (2010, p.117) "a engenharia de requisitos (ER) é uma ação da engenharia de software que começa durante a atividade de comunicação e continua durante a atividade de modelagem". Nessa definição, percebe-se o quanto é importante manter uma comunicação fluída entre as equipes, contudo é primordial saber o que se pretende desenvolver.

A criação de uma Matriz de Design Educacional para uma disciplina dentro do Sistema permite que o compartilhamento seja realizado para um grupo de usuários restrito. Esse grupo composto por um professor-formador, um designer educacional (DE) e um revisor é responsável pelo preenchimento do documento, sendo o DE o sujeito encarregado de conduzir todo o processo de elaboração da Matriz. Além disso, cabe a ele finalizar o documento e encaminhá-lo ao diagramador web. No quadro 2 , apresenta-se o papel dos usuários que participam do Sistema Made de acordo com seus perfis.

Quadro 2 - Funções gerais dos usuários no Made

\begin{tabular}{|l|l|}
\hline \multicolumn{1}{|c|}{ Perfil } & \multicolumn{1}{c|}{ Função } \\
\hline Administrador & $\begin{array}{l}\text { Administrar o Sistema com permissão ilimitada } \\
\text { Cadastrar e gerenciar usuários } \\
\text { Definir permissões dos usuários } \\
\text { Cadastrar e gerenciar matrizes }\end{array}$ \\
\hline Professor-formador & $\begin{array}{l}\text { Alterar os conteúdos da sua disciplina } \\
\text { Visualizar os conteúdos de seu interesse }\end{array}$ \\
\hline $\begin{array}{l}\text { Designer Educacional } \\
\text { (DE) }\end{array}$ & Gerenciar e editar os conteúdos de sua responsabilidade \\
\hline Revisor & Editar os conteúdos de sua responsabilidade \\
\hline Diagramador web & Visualizar as matrizes finalizadas \\
\hline $\begin{array}{l}\text { Coordenador de Curso/ } \\
\text { Coordenador de Tutoria }\end{array}$ & $\begin{array}{l}\text { Visualizar as matrizes finalizadas do curso pelo qual é } \\
\text { responsável }\end{array}$ \\
\hline Professor-tutor & $\begin{array}{l}\text { Visualizar as matrizes finalizadas da sua disciplina e os } \\
\text { conteúdos da sua área de interesse. }\end{array}$ \\
\hline
\end{tabular}


Os perfis se subdividem em três categorias de atuação dentro do sistema:

- Administrador - gerencia, cria e edita todos os campos do sistema.

- Usuário da matriz - edita os campos da matriz sob sua responsabilidade.

- Usuário - apenas visualiza as matrizes criadas.

As funcionalidades foram delimitadas conforme os papéis exercidos pelos atores da EaD no IFCE. Contudo, após as validações e teste do sistema, esses papéis podem ser ajustados e readequados as necessidades da equipe multidisciplinar. O processo de construção do Sistema Made considerou o uso de tecnologias atuais que possibilitam a criação, desenvolvimento, implementação e execução de forma rápida e satisfatória, atendendo, sobretudo, as necessidades de tempo para a finalização desta pesquisa. Além disso, buscou incorporar tecnologias já em uso no Ambiente Virtual de Aprendizagem utilizado pela $\mathrm{DEaD} / \mathrm{IFCE}$, o Moodle.

A interface inicial do sistema dispõe de uma tela de usuário e senha, na qual a pessoa, previamente cadastrada, realiza seu login no sistema e inicia suas atividades. $\mathrm{Na}$ figura 2, será visto na tela de login o espaço para usuário, que corresponderá ao CPF (Cadastro Pessoa Física) por ser a mesma identificação usada no acesso ao AVA, e para adotará senha, que inicialmente será uma sequência padrão para todos os usuários, que poderá ser alterada por eles através de seu perfil dentro na plataforma.

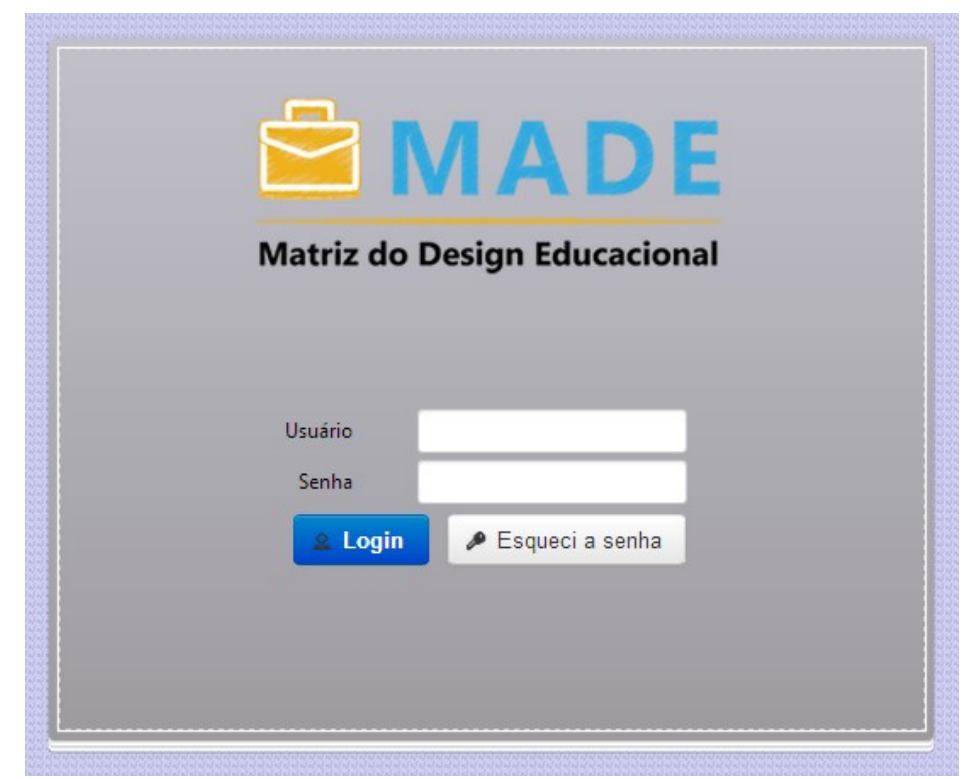

Figura 2 - Tela de login

Fonte: Sistema Made 
Ao realizar o login no sistema, o professor-formador visualizará a tela inicial com a lista das disciplinas de que ele é responsável. Já o administrador visualizará o menu de gerenciamento do sistema conforme figura a seguir.

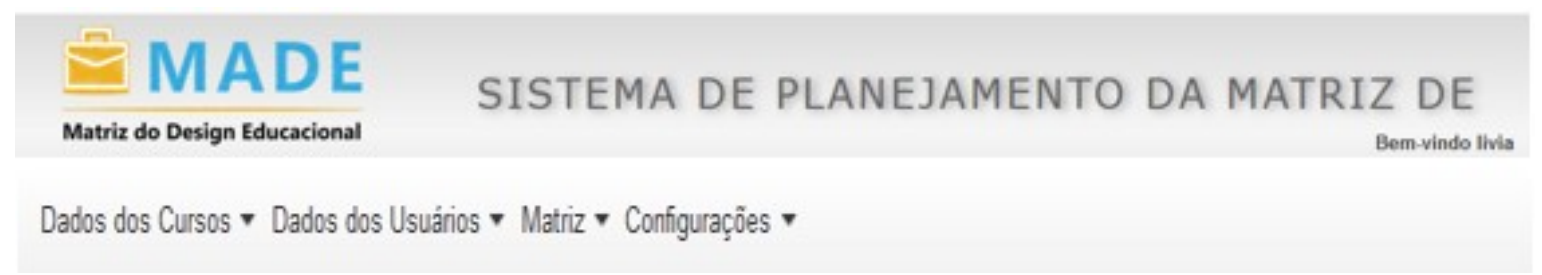

Figura 3 - Menu de administração do sistema

Fonte: Sistema Made

No menu "Dados dos cursos", o administrador encontra os seguintes submenus: programa, polo, curso, disciplinas e tipo de curso (técnico, graduação, especialização, extensão e capacitação). Nesses submenus, o administrador insere todos os dados referentes aos programas educacionais ofertados pela Diretoria de EaD. Para isso, será identificado o "Nome" e "Sigla" do programa. Posteriormente esses dados serão utilizados para vincular os cursos, disciplinas e polos.

No menu "Dados dos usuários", o administrador encontra os seguintes submenus: usuários, grupos de usuários, tipo de usuário da matriz (formador, designer, revisor, etc.) e tipo de formação (graduação, especialização, mestrado e doutorado). Nesses submenus, o administrador realiza todo o gerenciamento das contas dos usuários.

No menu "Matriz" o administrador encontra o seguinte submenu: "Gerenciar matriz". Nesse campo, é possível encontrar todas as matrizes criadas no sistema, bem como criar uma nova matriz ou editar uma já existente.

O menu "Configurações" possibilita ao administrador gerenciar as permissões e/ou modificar as nomenclaturas do sistema.

\section{ESTRUTURA DE GERENCIAMENTO DO SISTEMA MADE}

O gerenciamento do Sistema divide-se em três módulos: criação, edição e publicação. A criação é referente à preparação do ambiente, cadastro de todos os usuários e matrizes a serem utilizadas nos cursos; edição corresponde à fase de preenchimento dos campos da Matriz De Design Educacional pelos atores 
responsáveis; e a publicação corresponde à fase final, momento em que todas as validações foram realizadas e a Matriz recebe o aval do Designer Educacional para exportação.

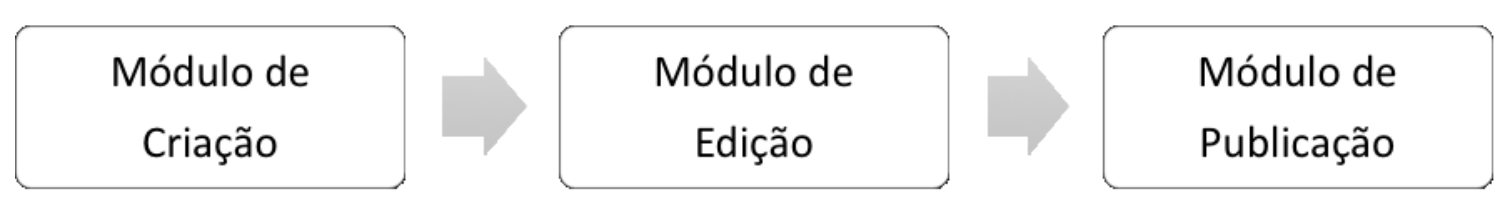

Figura 3 - Módulos do Sistema Made

Fonte: Elaborada pelas autoras.

O administrador do sistema é encarregado pela criação da Matriz por disciplina. Essa criação ocorre em consonância com as atividades de planejamento da equipe de produção de material didático e das coordenações de curso. As informações contidas nessa etapa dizem respeito ao programa, curso, semestre, disciplina, período da oferta e turma. Na figura 4, veremos a tela do sistema onde esses dados são inseridos.

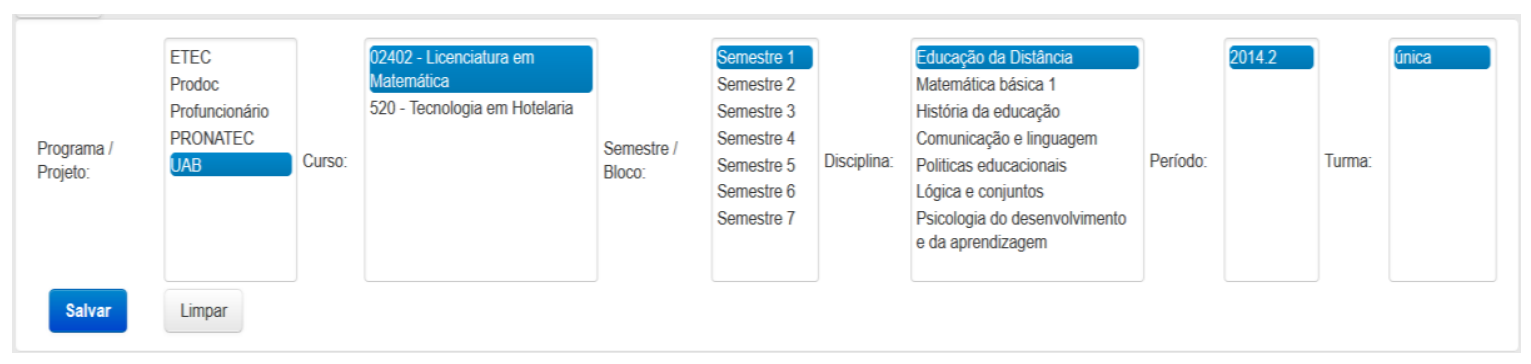

Figura 4 - Tela de criação/edição de uma Matriz

Fonte: Sistema Made

O módulo de Criação é a etapa inicial do processo de concepção da Matriz de Design Educacional e é definido em semestre anterior à oferta da disciplina. O administrador do sistema recebe da equipe de produção a lista de disciplinas que serão ofertadas e realiza a criação das matrizes correspondentes a essas disciplinas. Na tela apresentada na figura 5, observa-se a lista das matrizes criadas no sistema. 


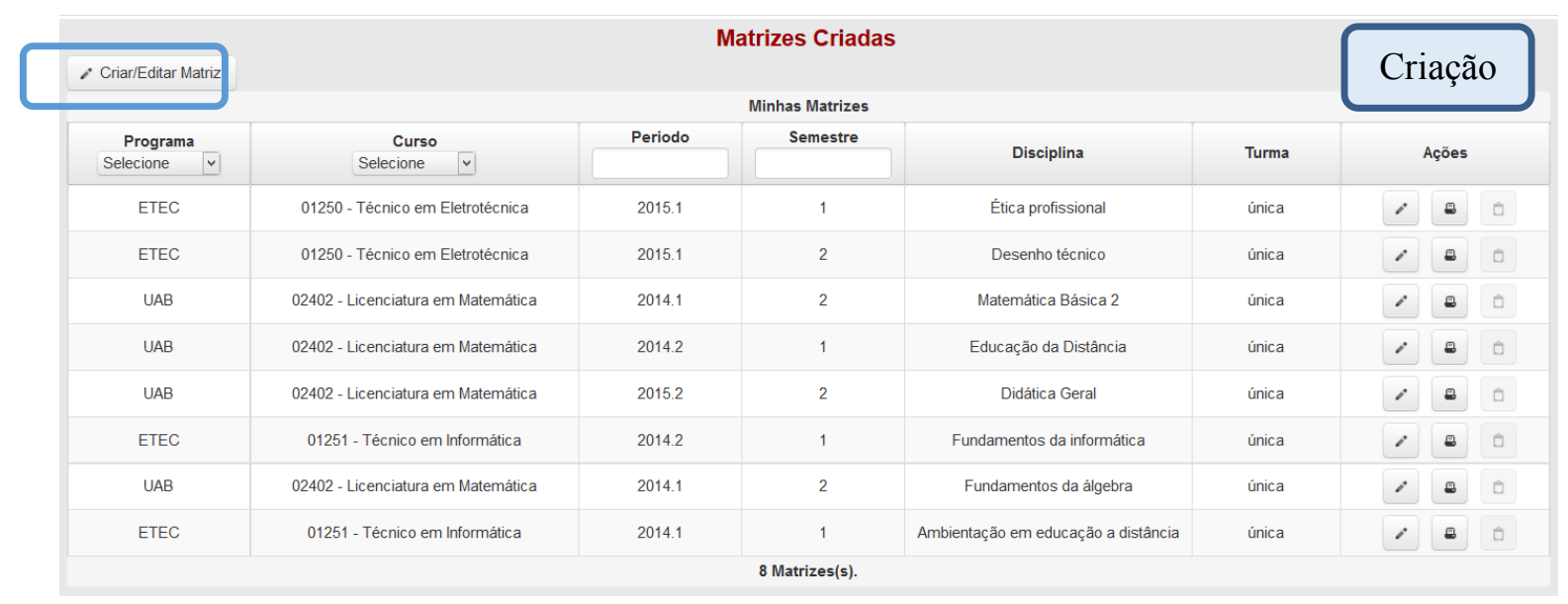

Figura 1 - Lista de matrizes criadas

Fonte: Sistema Made

A identificação dessas matrizes é feita pelos seguintes campos: programa, curso, período, semestre, disciplina e turma. O período corresponde ao momento da oferta e o semestre obedece à ordem em que a disciplina está organizada na Matriz Curricular do curso.

No botão "Criar/Editar Matriz" (destacado em azul), o administrador pode criar uma nova matriz ou editar os campos de uma matriz já criada. Já na coluna "Ações", o usuário da matriz pode realizar três tipos de tarefas: $1^{\text {a }}$ "editar" os campos da matriz da disciplina especificada; $2^{\mathrm{a}}$ imprimir matriz; e $3^{\mathrm{a}}$ solicitar ao administrador a reabertura da matriz para que possa realizar modificações. Esse último procedimento é acionado quando a matriz desejada já tiver sido finalizada.

Durante a criação de uma matriz, o administrador vincula os responsáveis pela disciplina e os atores encarregados do preenchimento da matriz. Cabe ressaltar que os responsáveis pela edição da Matriz são professor-formador, designer educacional e revisor. Demais dados dos usuários são de caráter informacional e necessários para cadastro no ambiente virtual, como é o caso dos tutores a distância. Ao clicar em um dos botões da figura anterior, surge a tela (figura 6) com a lista de usuários cadastrados no sistema. 


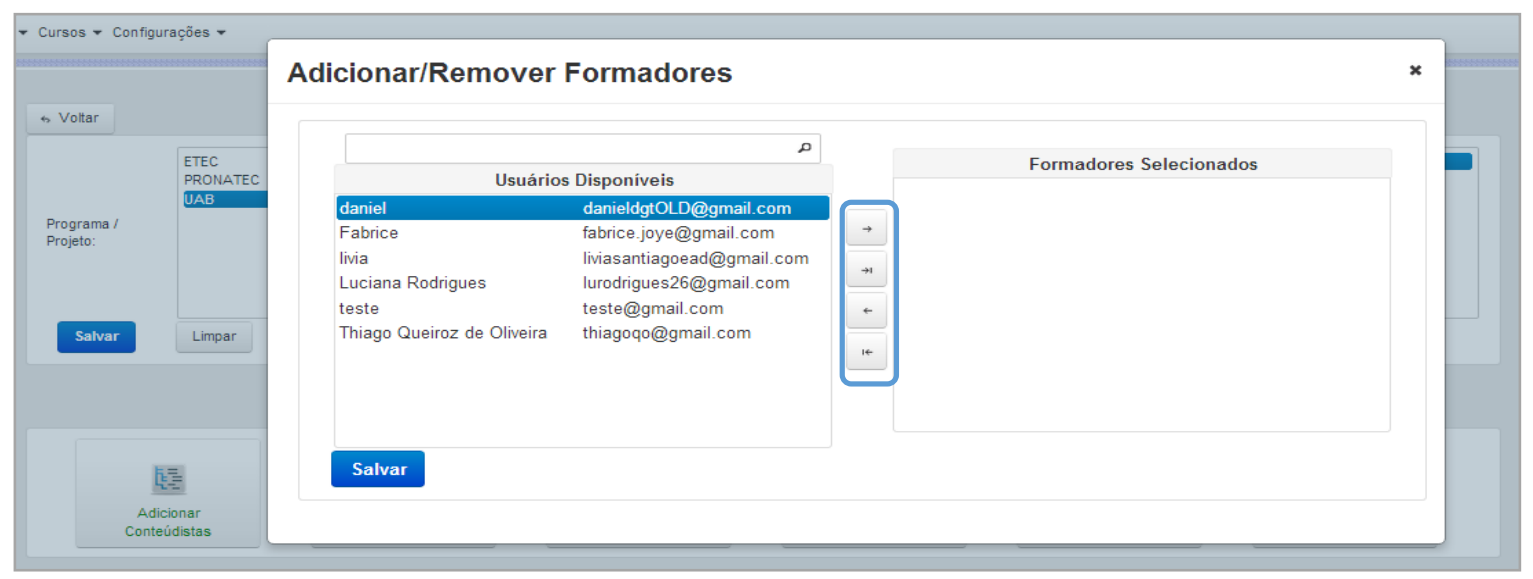

Figura 6 - Adicionar/Remover usuário

Fonte: Sistema Made

O administrador deve selecionar o usuário, conforme lista disponibilizada pela equipe de produção, e vinculá-lo à sua função dentro da Matriz específica. Essa vinculação pode ser realizada de duas formas: 1. Selecionando o usuário e arrastando com o mouse para a coluna da direita ou 2. Selecionando o usuário e clicando no primeiro botão do menu destacado em preto. Para adicionar mais de um usuário, basta selecionar os usuários desejados e clicar no segundo botão do menu destacado em preto. Em seguida, deve-se clicar no botão "Salvar" para encerrar o processo de adição de usuários.

Para criação da matriz de uma disciplina, é necessário que, em momento anterior, o administrador tenha cadastrado o programa, curso, semestre/bloco e disciplina. $\mathrm{O}$ cadastro dos usuários pode ser feito em momento posterior à criação das matrizes, o que permite ao administrador e equipe pedagógica antecipar alguns processos no planejamento das ofertas disciplinares. Contudo a visualização ou edição de uma matriz depende da vinculação de seus responsáveis.

Três atores atuam diretamente nessa área de edição dos conteúdos, são eles professor-formador, designer educacional e revisor. O professor formador é responsável pelo preenchimento de todos os campos da matriz e tem a orientação pedagógica do DE. Após a edição pelo formador e análise do DE, o revisor é encarregado de corrigir os textos e indicar, quando necessário, alterações de ordem linguística e textual. 


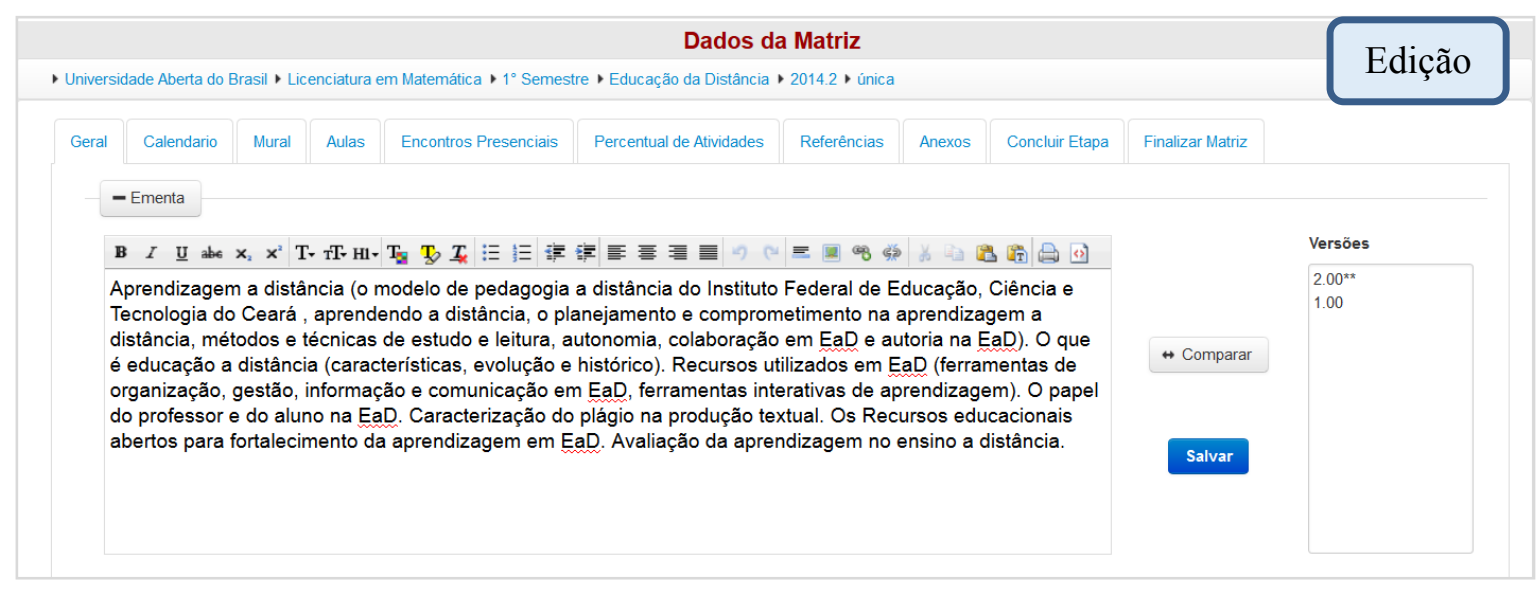

Figura 7 - Matriz em construção

Fonte: Sistema Made

Após todas as correções, edições e validações realizadas entre professorformador, DE e revisor, a matriz é exportada para um arquivo de texto ou PDF. Essa ação está sob a responsabilidade do DE e é realizada através do botão "Finalizar Matriz".

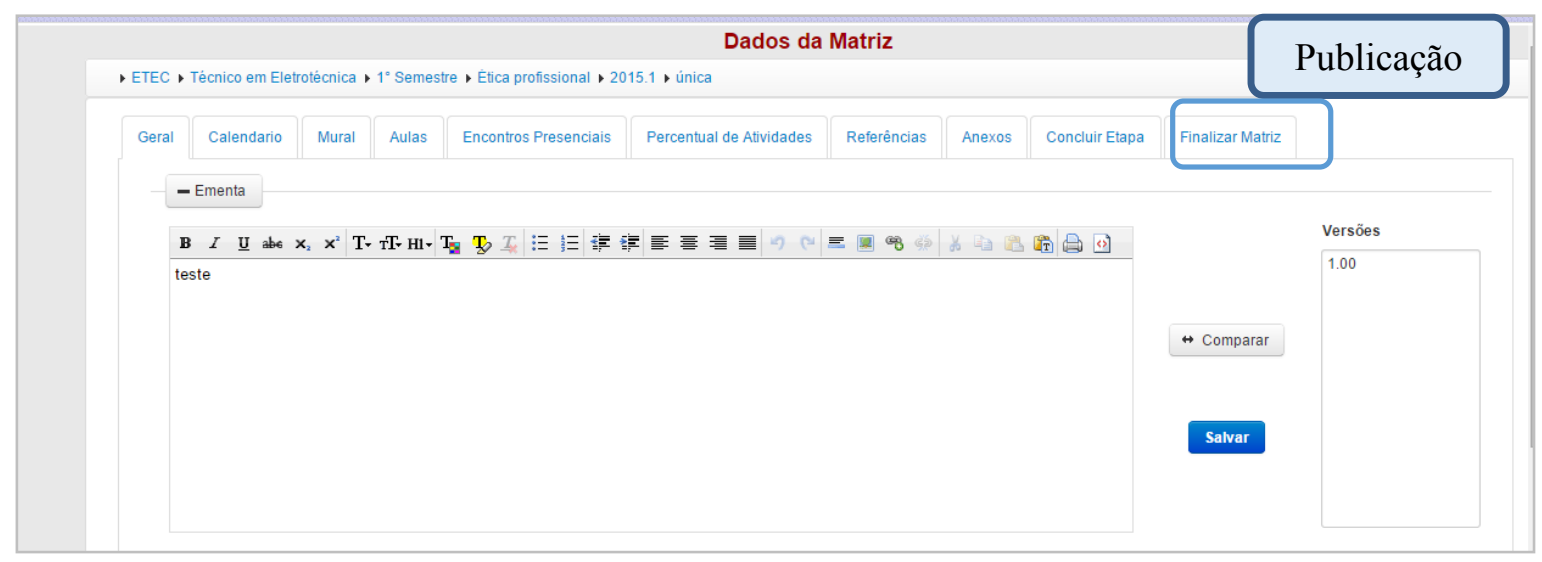

Figura 8 - Módulo de publicação

Fonte: Sistema Made

No modelo atual de produção, o DE desempenha o papel de finalização da matriz e a envia à equipe técnica que cuida da postagem e configuração da disciplina no ambiente virtual de aprendizagem. Dessa forma, a ação de finalização de uma matriz no sistema Made ficou a cargo do DE. 


\section{CONSIDERAÇÕES FINAIS}

O Made encontra-se em fase de teste e, como se trata de um sistema em evolução, muitas informações podem ser agregadas ao seu escopo à medida que os usuários iniciarem seu uso. Acreditamos que a utilização por uma grande quantidade de usuários permitirá não somente elencar melhorias para o sistema, mas repensar a fase de planejamento como fase fundamental para a oferta de cursos a distância.

Por se tratar de um sistema em fase de desenvolvimento, muitas ideias surgem a partir de sua aplicação junto à equipe multidisciplinar da DEaD/IFCE. Dentre elas, destaca-se

1. Com a evolução técnica do sistema, dados estatísticos sobre a produção poderão ser extraídos e analisados, no intuito de se criarem estratégias técnicas, pedagógicas ou administrativas que minimizem os entraves durante a elaboração do planejamento sejam de um curso ou disciplina.

2. Outra possibilidade futura, a partir da utilização do sistema pelo público-alvo, é a coleta de dados para a delimitação de melhorias no sistema. Como ponto de partida, podem-se estudar formas de incorporar outras ferramentas de gestão, tais como SIGEST (Sistema de Gestão e Administração da DEaD) e SISAVI (Sistema de Avaliação Institucional).

3. O Sistema Made pode ser utilizado como apoio ao planejamento das disciplinas na modalidade presencial, observando que serão necessários fazer ajustes no sistema para as devidas adequações ao modelo presencial.

A aplicação do Sistema Made no contexto da Diretoria de Educação a Distância do IFCE possibilite a seus atores sistematizar seus processos, gerenciar seus trabalhos e organizar o fluxo de mensagens geradas durante a elaboração e planejamento da Matriz de Design Educacional.

Ressaltamos que a centralização, em um espaço único, de todas as etapas realizadas para produção desse planejamento, contribuirá para a gestão da informação pela equipe multidisciplinar e possibilitará a coordenação de produção realizar um acompanhamento pedagógico e sistêmico de todo o processo, bem como dos atores envolvidos. Assim se poderão rever e alinhar, da melhor forma possível, as etapas de concepção da Matriz. 


\section{REFERÊNCIAS}

BEHAR, P. A. Modelos pedagógicos em educação a distância. In: BEHAR, P. A. Modelos pedagógicos em educação a distância. Porto Alegre: Artmed, 2009.

FILATRO, A. Design Instrucional Contextualizado: educação e tecnologia. São Paulo: Editora Senac, 2003.

GUEDES, J. F. Produção de material didático para EaD no Curso de Licenciatura em Matemática: o caso da UAB/IFCE. Dissertação (Mestrado) - Universidade Federal do Ceará (UFC), Programa de Pós-graduação em Educação Brasileira, Área de Concentração: Tecnologias digitais na educação, Fortaleza, CE, 2010.

JOYE, C. R.;YOUNG, R. S. Educação a Distância. Fortaleza: UAB/IFCE, 2013.

PAQUETTE, G. L'ingénierie pédagogique à base d'objets et le référencement par les compétences. International Journal of Technologies in Higher Education. 2004. Disponível em $\quad<\mathrm{http}$ :/hal.archivesouvertes.fr/docs/00/05/56/37/PDF/art4Paquette.pdf>. Acesso em: 18 jan. 2018.

PRESSMAN, R. S. Engenharia de Software. $6^{\text {a }}$ ed. São Paulo: Editora Mcgraw-hill Interamericana, 2010.

SPANHOL, F. J. Aspectos do gerenciamento de projetos em EAD. In: Litto, F. M \& Formiga, M (org). Educação a Distância: o estado da arte. São Paulo: Pearson, 2009. 
